\title{
A CURRENT T-T-T DIAGRAM FOR WROUGHT ALLOY 718
}

\author{
Armida Oradei-Basile ${ }^{*}$ and J. F. Radavich \\ School of Materials Engineering, Purdue University \\ West Lafayette, IN 47907
}

\begin{abstract}
A T-T-T study was carried out on the phase reactions in high quality wrought alloy 718 billet. Samples were exposed from $1200^{\circ} \mathrm{F}$ to $1700^{\circ} \mathrm{F}$ for times of 0.1 hour to 50 hours. The only phases found and plotted on the T-T-T diagram were $\gamma, \gamma^{\prime \prime}$, and delta phases. The $\gamma, \gamma^{\prime}$, delta, $\alpha \mathrm{Cr}$, and sigma phases found in a previous longtime study were plotted as extensions on the same T-T-T diagram. In longtimes and under stress, the transition of $\gamma^{\prime \prime}$ to $\gamma^{\prime}+$ delta occurs below $1200^{\circ} \mathrm{F}$.
\end{abstract}

* Berrita, USA. 


\section{Introduction}

The first T-T-T diagram for wrought alloy 718 was presented by Eiselstein in 1965(1). This diagram contained curves for $\mathrm{MC}$, Laves, $\gamma, \mathrm{Ni}_{3} \mathrm{Cb}$, and $\mathrm{M}_{6} \mathrm{C}$. However, the composition of early material used by Eiselstein as well as the thermal history have changed over the years and all the phases Eiselstein reported are not currently found. It is now accepted that the Laves phase is a solidification phase and is normally not found in homogenized material. The MC phase forms on solidification and is stable at all temperatures except when material is solutioned at temperatures above $2200^{\circ} \mathrm{F}$. The early $\mathrm{M}_{6} \mathrm{C}$ phase reported was found in 718 material which contained very high $\mathrm{Si}$ contents, and in most current materials, the Si content is about $0.1 \%$ and $\mathrm{M}_{6} \mathrm{C}$ is not detected.

In the mid-sixties, a longtime study by Barker, et al. (2) showed that the delta phase would form at lower temperatures as a result of the transition of $\gamma^{\prime \prime}$ and $\gamma^{\prime}$ to the dclta phase. In addition, instead of the expected $\mathrm{M}_{23} \mathrm{C}_{6}$ phase forming at the grain boundaries, an $\alpha \mathrm{Cr}$ and sigma phase formed in the longer times under stress. While a small amount of Laves was reported, its presence was questionable as the starting material showed segregation. In 1969 Decker presented a more up-to-date T-T-T diagram which only included $\gamma^{\prime \prime}, \gamma^{\prime}$, and delta phases (3).

In the 1968 Seven Springs meeting, Boesch and Canada showed that the delta phase formed in shorter times than that reported by Eiselstein (4). More recently in the 1988 Seven Springs meeting, Brooks and Bridges studied the behavior of phases in alloy 718 which was exposed up to 10,000 hours in a temperature range of $500^{\circ} \mathrm{C}$ to $1000^{\circ} \mathrm{C}$ (5). In the 10,000 hour exposed material they confirmed the $\alpha \mathrm{Cr}$ phase at the grain boundaries, but no Laves was present. Their T-T-T diagram contained one curve for delta formed by the initial solutioning heat treatment and one curve for the delta which formed at the grain boundaries during the $\gamma^{\prime \prime}$ to $\gamma+$ delta transition. 
From all the published literature on alloy 718 , it is clear that the beginning of precipitation and the type of the precipitate is dependent on the nature of the starting material, i.e. the degree of residual strain, the amount of delta produced by the solutioning step, and probably the most important is the degree of $\mathrm{Nb}$ segregation left after the processing cycles. The current T-T-T study was undertaken to assess the phase reactions in uniform grain size billet material which was considered to be fully homogenized but still contains a certain amount of strain produced by forging.

\section{Procedure}

The wrought 718 material used in this study was supplied by Wyman-Gordon Company. The material had a nominal 718 composition with $5.38 \mathrm{Nb}$ and $0.07 \mathrm{Si}$ and represents high quality forged material. The billet material showed an irregular matrix precipitation and delta phase at the grain boundaries. After a study to determine the delta solvus and beginning of grain growth, the as-received material was given a 15 minute heat treatment at $1835^{\circ} \mathrm{F}$. This solutioned the matrix precipitation but minimized the grain growth by retention of enough delta particles at the grain boundaries. Phase cxtraction and identification showed that MC, delta, and some TiN phases were present in the starting material. No Laves was found.

Samples were first soaked for 10 minutes at temperature prior to the indicated times of exposures. Samples were exposed from 0.1 to 50 hours in a temperature range of $1200^{\circ} \mathrm{F}$ to $1700^{\circ} \mathrm{F}$ and water quenched. All the samples were electrolytically polished and etched with a $\mathrm{CrO}_{3}$ solution. While the sample preparation technique used in this study is considered to be optimum to show the finest precipitation, the limit of SEM resolution made detection difficult of the initial precipitation present at the lower temperatures. 


\section{Results}

The phases found in this study by isothermal treatments up to 50 hours are $\gamma, \gamma^{\prime \prime}$, and delta phases and are plotted as curves on the T-T-T diagram (Fig. 1). No Laves, $\mathrm{M}_{6} \mathrm{C}$ or $\alpha \mathrm{Cr}$ phases were found in 50 hours of exposure, but $\alpha \mathrm{Cr}$ and sigma phases have been found in very longtimes and are plotted on the extended portion of the T-T-T diagram. The structural results found in this study reflect the behavior of small samples which were given various single heat treatments. In large components, the nose of the curves will shift to the longer times, but the shape of the curves should be similar.

Figure 2 shows the precipitation in the billet in the as-received condition and after a solution of 15 minutes at $1835^{\circ} \mathrm{F}$. Figure 3 shows the uniform starting grain structure at $100 \mathrm{X}$.

The early stages of precipitation at $1200^{\circ} \mathrm{F}$ and $1300^{\circ} \mathrm{F}$ are difficult to resolve with the SEM even at $30,000 \mathrm{X}$ (Fig. 4). After 100 hours at $1200^{\circ} \mathrm{F}$ the precipitation appears to be irregular and is difficult to see. The uniform precipitation formed in 10 hours at $1300^{\circ} \mathrm{F}$ appears to round and is very small. This precipitation can be either $\gamma$ or $\gamma^{\prime}$ or both, and only after 50 hours at $1300^{\circ} \mathrm{F}$ can one see round $\gamma$ and disk shaped $\gamma^{\prime}$ particles. A small amount of $\gamma^{\prime \prime}$ to $\gamma+$ delta transition is first noted after 10 hours at $1400^{\circ} \mathrm{F}$, found after 1 hour at $1500^{\circ} \mathrm{F}$ and after $1 / 2$ hour at $1600^{\circ} \mathrm{F}$. With longer exposures at $1600^{\circ} \mathrm{F}$, the amount of the $\gamma^{\prime \prime}$ phase decreases rapidly as the $\gamma$ and delta phases become prominent. An occasional round $\gamma$ particle is seen in short times at $1700^{\circ} \mathrm{F}$.

Figure 5 shows the nature of the transition structures after 50 hours at $1400^{\circ} \mathrm{F}, 1500^{\circ} \mathrm{F}$, $1600^{\circ} \mathrm{F}$ and $1700^{\circ} \mathrm{F}$. It can be seen that more $\gamma+$ delta phases are present with increasing temperature. At $1700^{\circ} \mathrm{F}$, the only phase present after 50 hours is delta.

From the longtime study of Barker, et al., the transition to $\gamma+$ delta occurs in in stressed material at lower temperatures than found in this study, (Fig. 6). If the temperature is raised to $1350^{\circ} \mathrm{F}$ and the samples undergoes longtime stress, the transition struc.ure is void of $\gamma^{\prime \prime}$, and $\gamma$, delta, $\alpha \mathrm{CCr}$, and sigma phases are present (Fig. 7). 


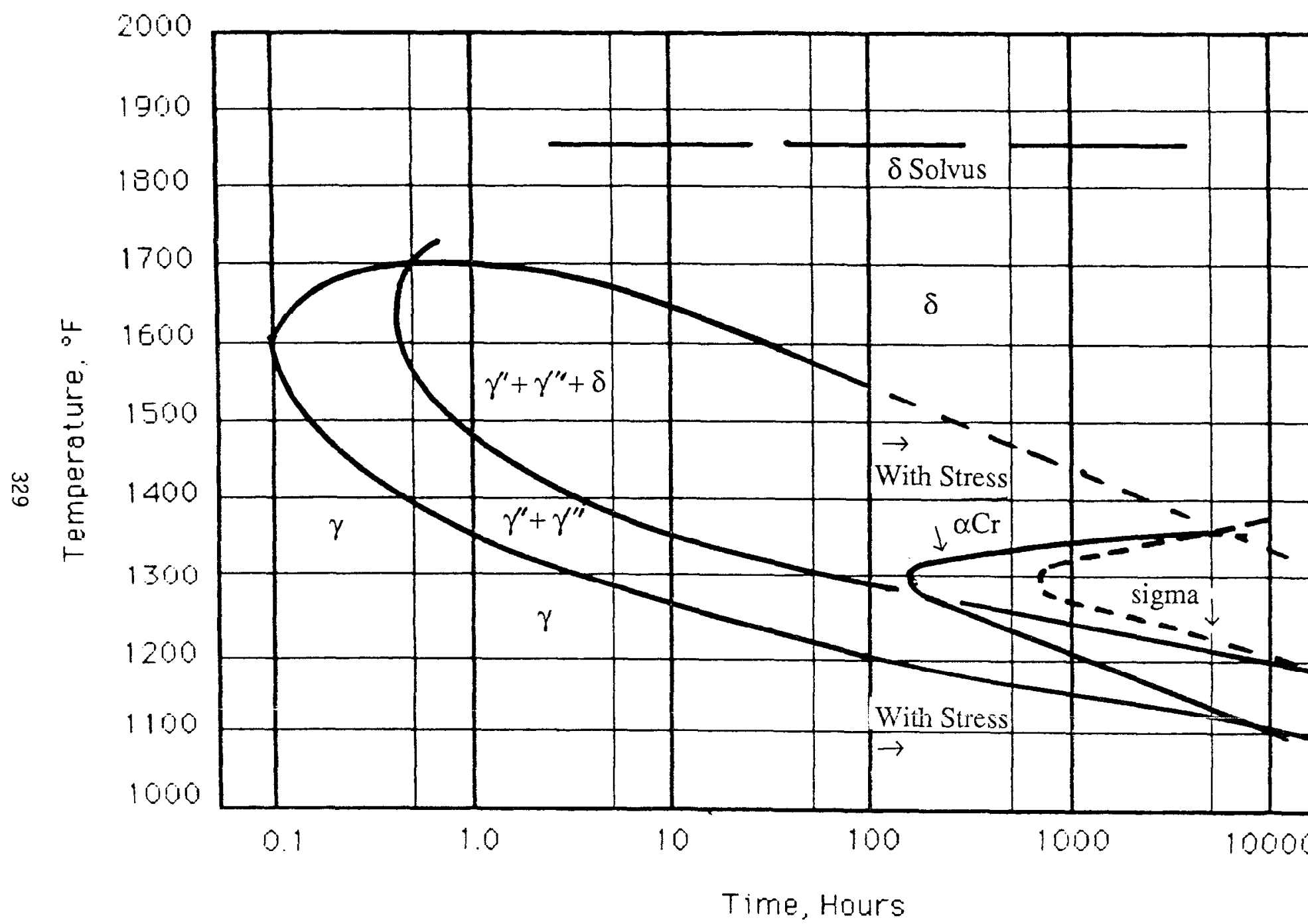

Figure 1. Time Temperature Transformation Curve for Alloy 


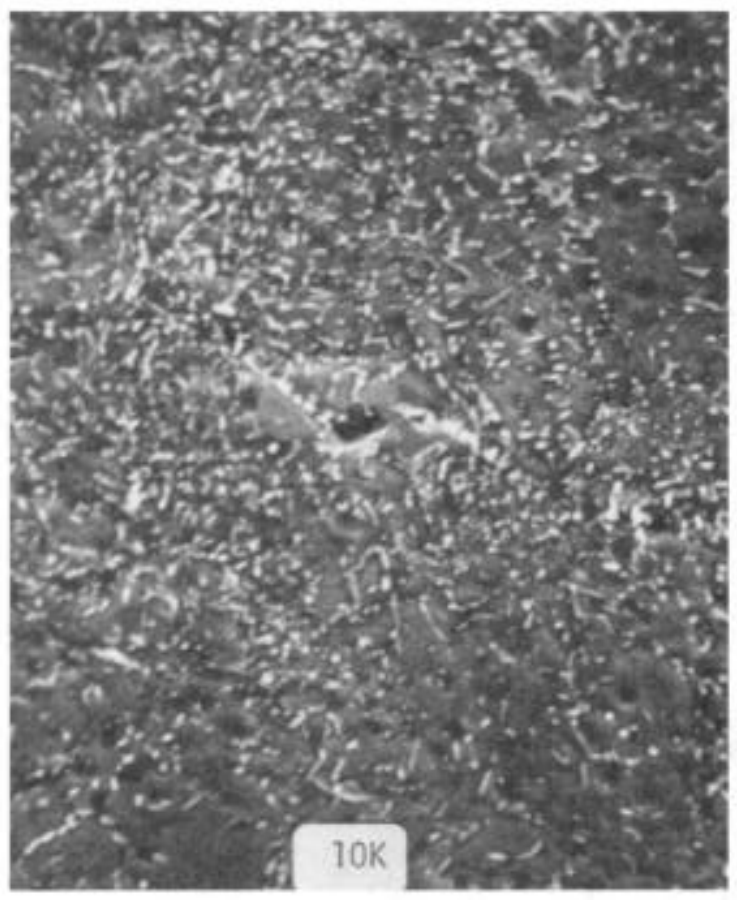

As-Received

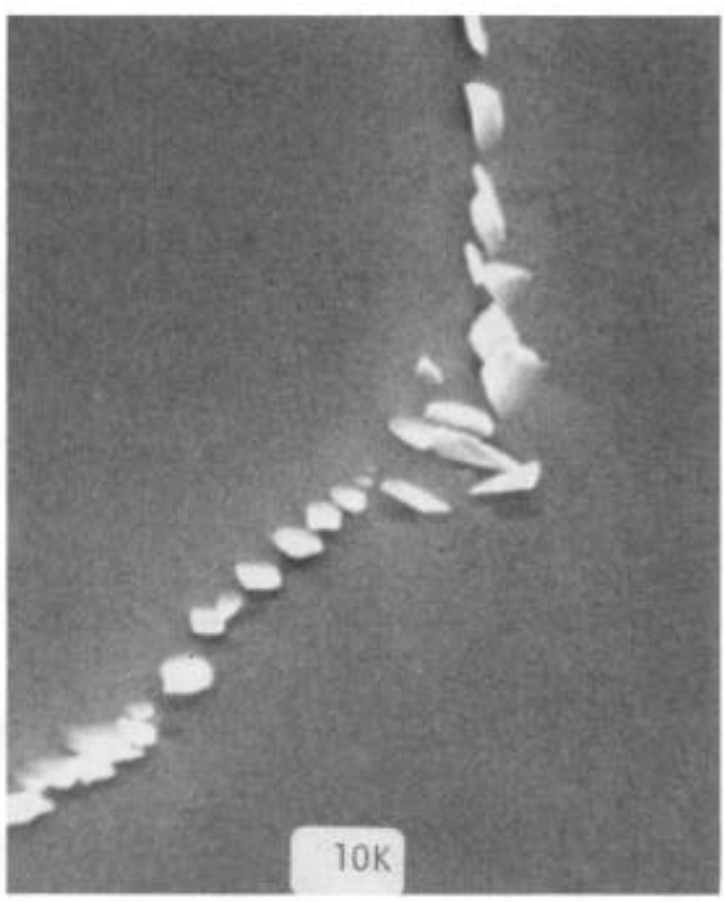

$1835^{\circ}$ Solutioned

Figure 2

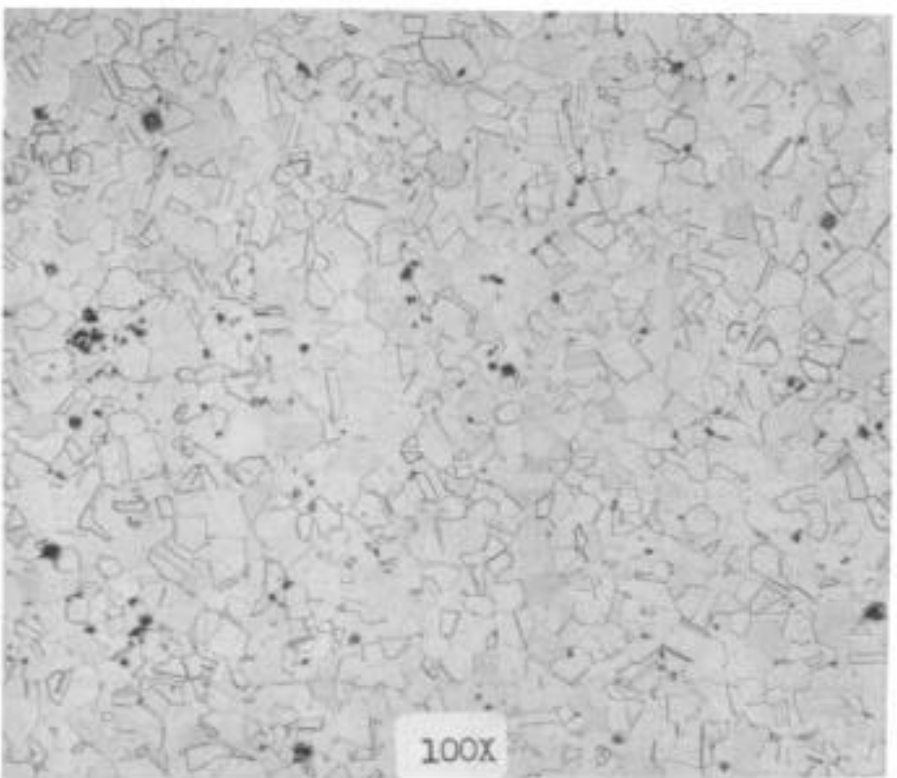

Starting Structure

Figure 3 


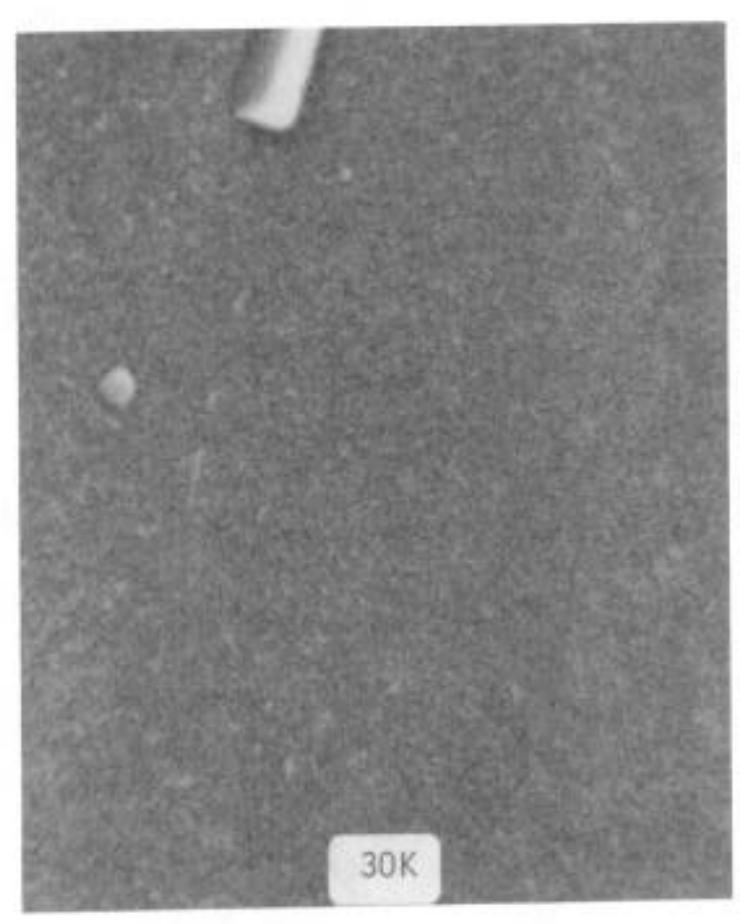

$1200^{\circ} \mathrm{F} / 100 \mathrm{hrs}$.

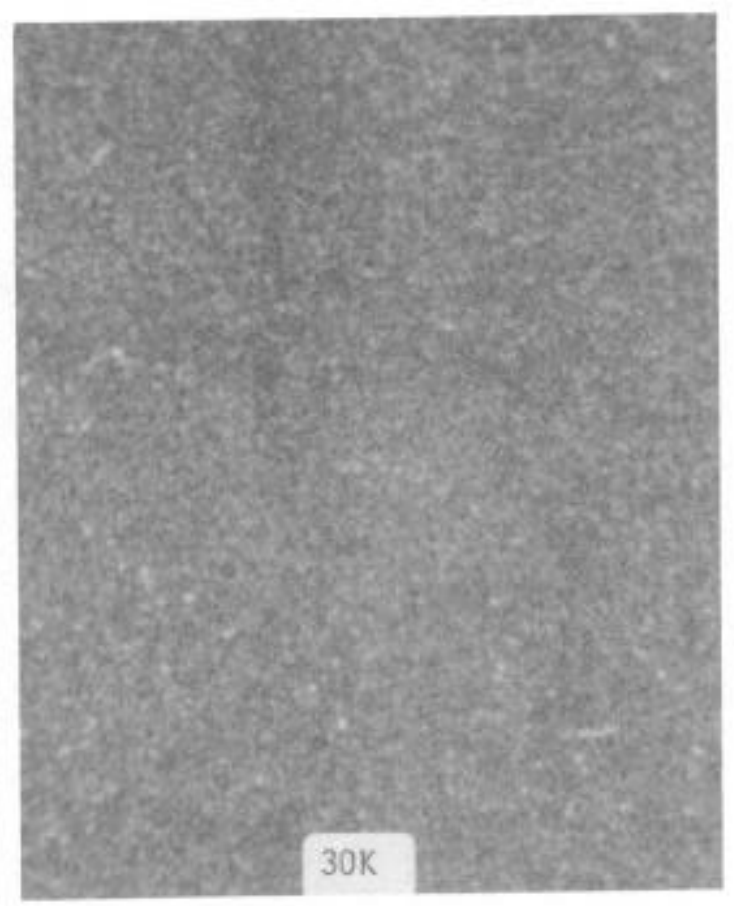

$1300^{\circ} \mathrm{F} / 10 \mathrm{hrs}$.

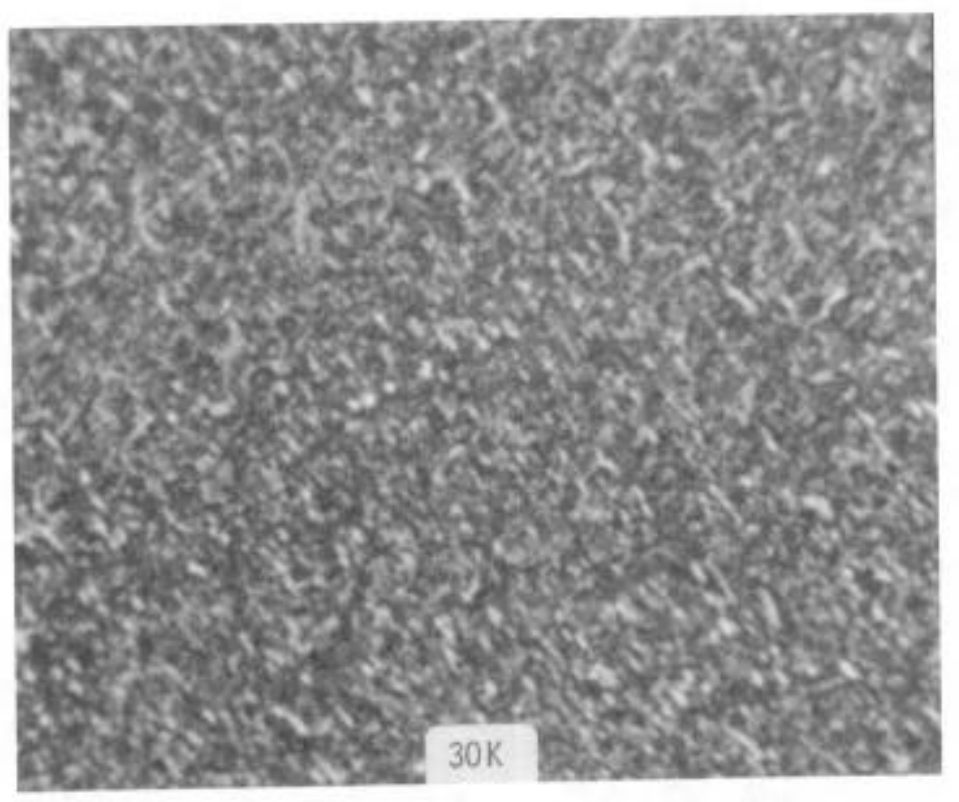

$1300^{\circ} \mathrm{F} / 50$ hrs.

Figure 4 


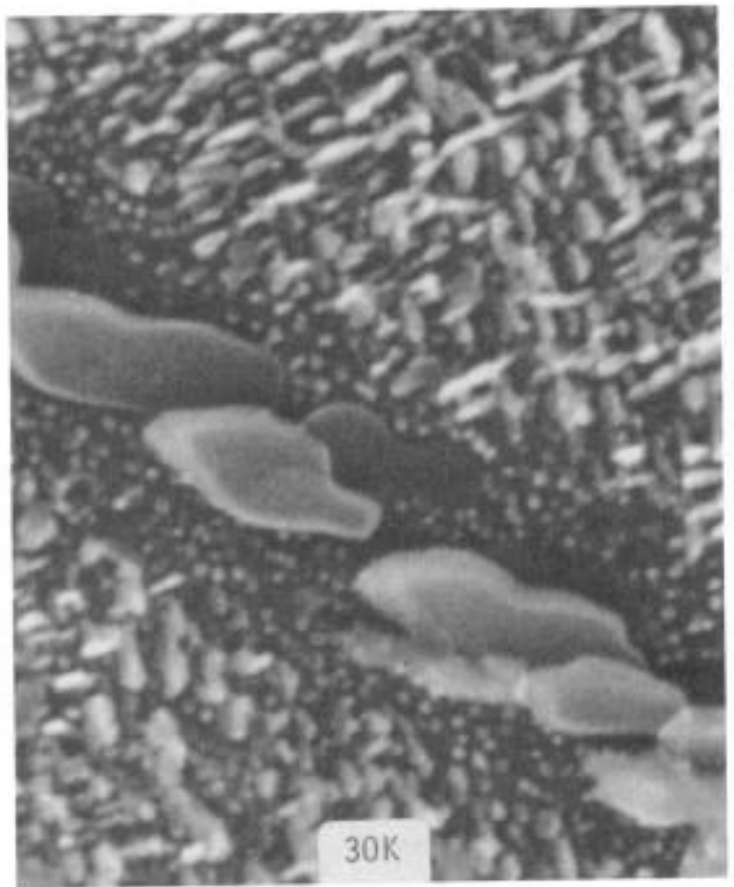

$1400^{\circ} \mathrm{F} / 50 \mathrm{hrs}$.

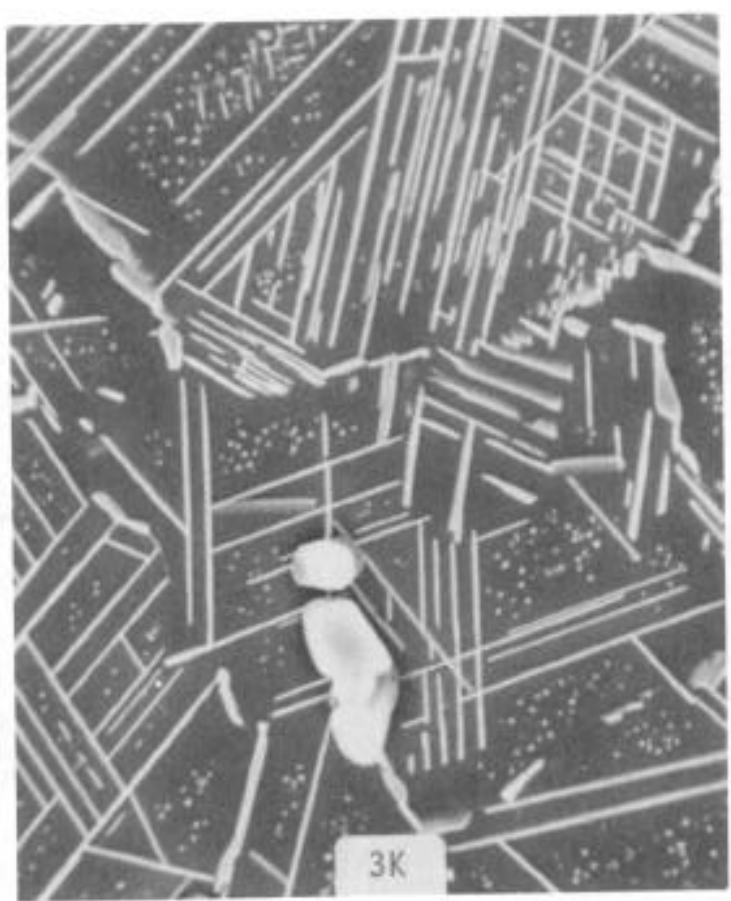

$1600^{\circ} \mathrm{F} / 50 \mathrm{hrs}$.

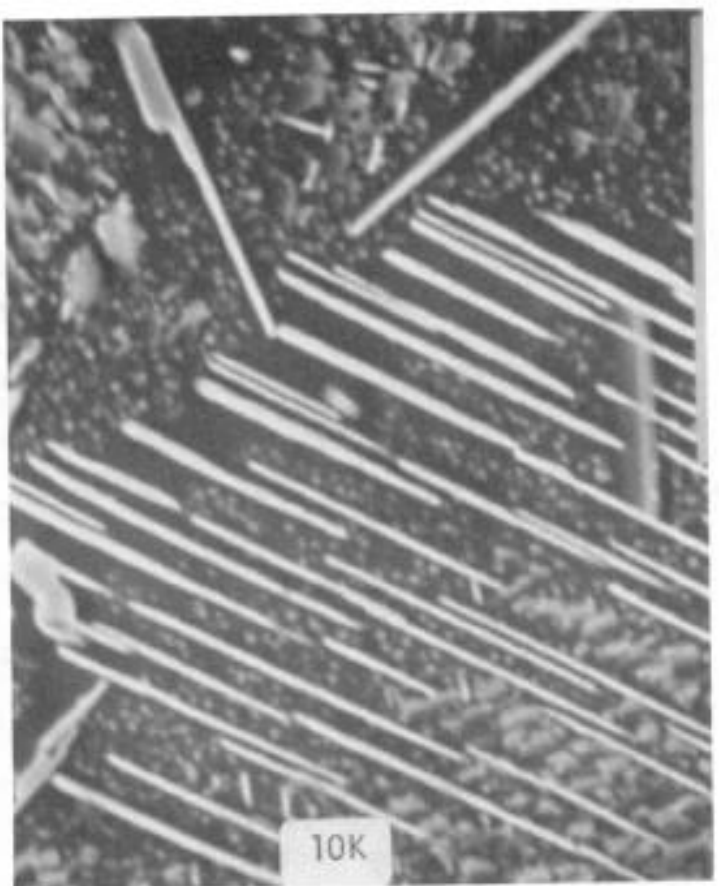

$1500^{\circ} \mathrm{F} / 50 \mathrm{hrs}$.

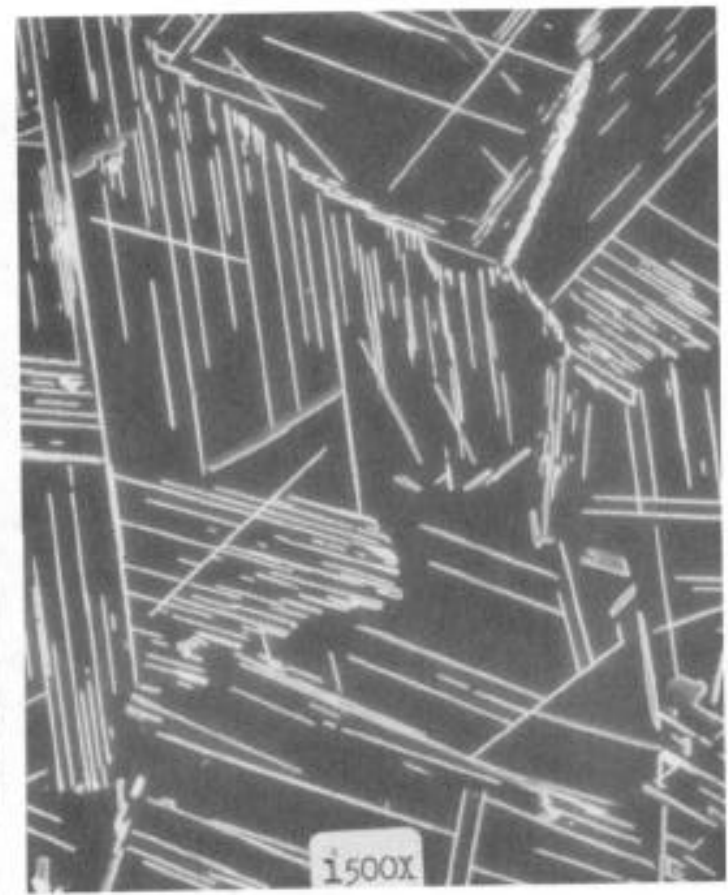

$1700 \% / 50 \mathrm{hrs}$

Fiqure 5 


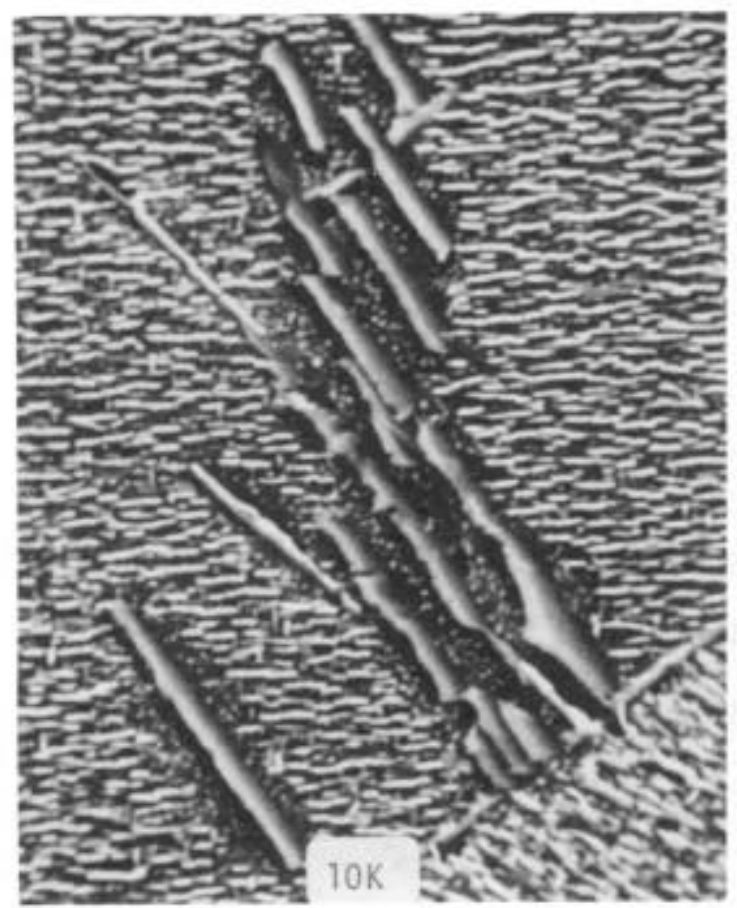

$1200^{\circ} \mathrm{F} / 63 \mathrm{KSI} / 10,333 \mathrm{hrs}$

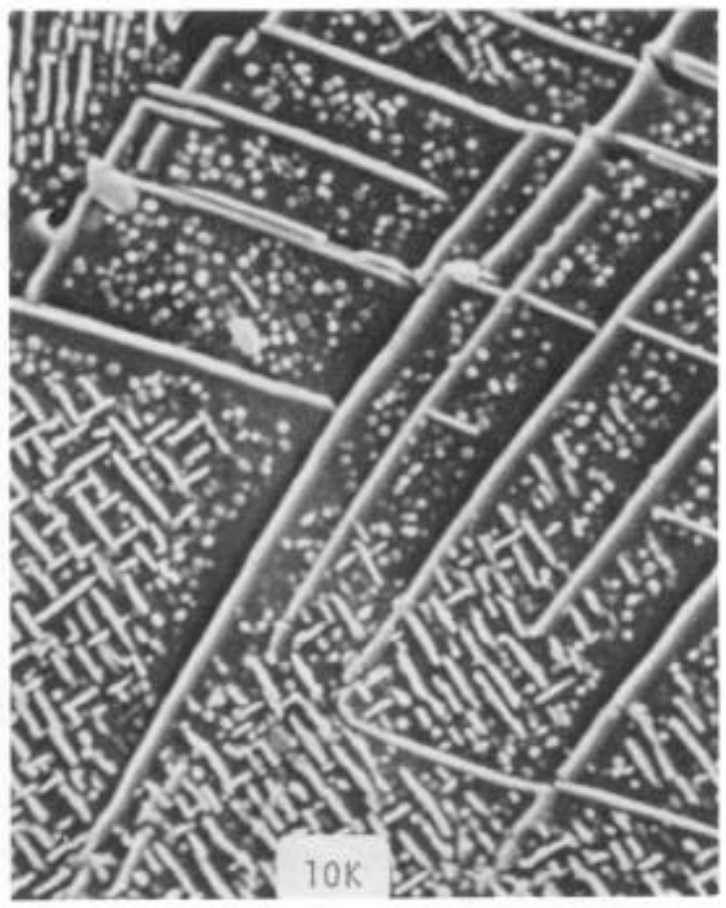

$1300^{\circ} \mathrm{F} / 37 \mathrm{KSI} / 6048 \mathrm{hrs}$

Figure 6
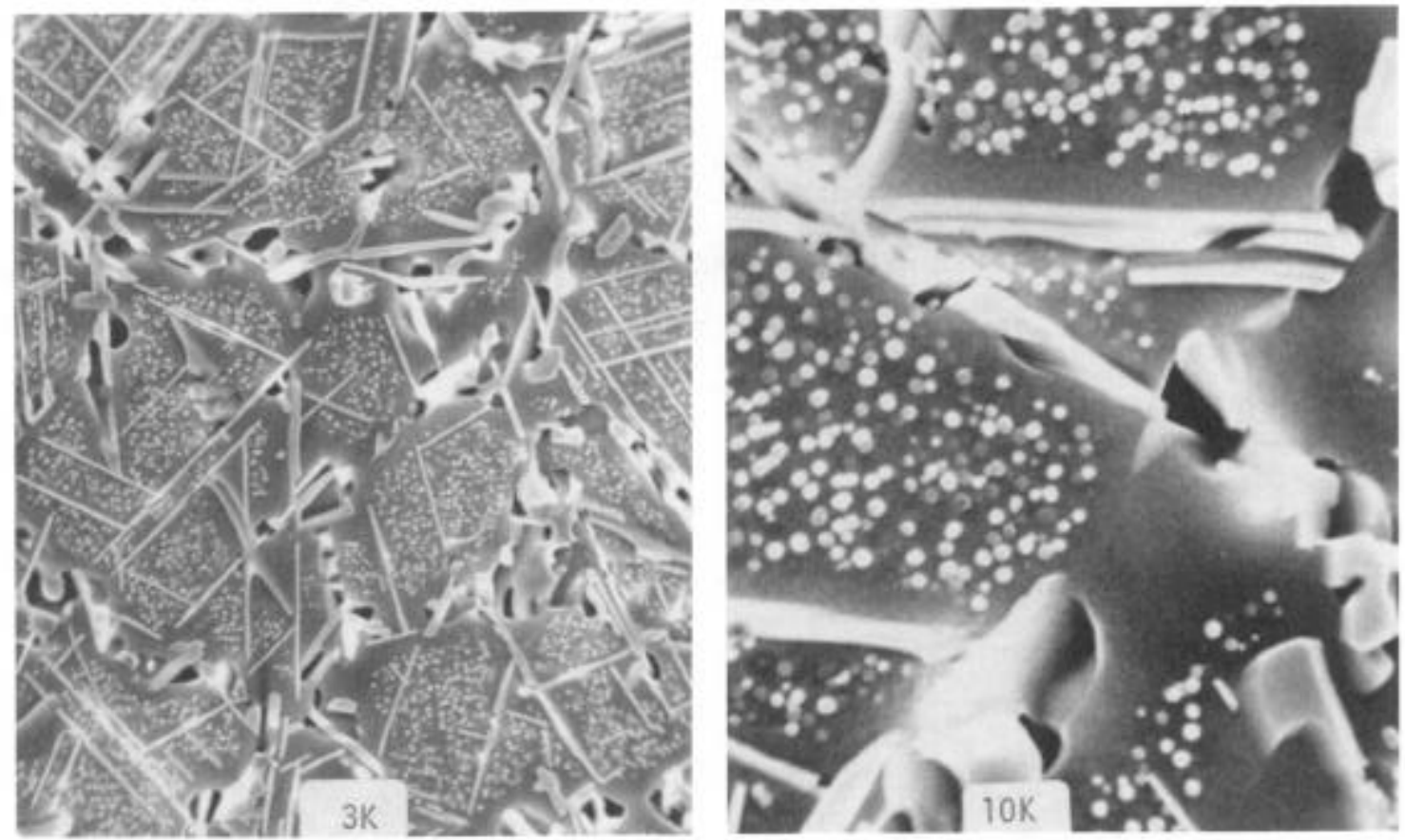

$1350^{\circ} \mathrm{F} / 10 \mathrm{KSI} / 5470 \mathrm{hrs}$

Figure 7 


\section{Conclusions}

The results of this study showed that in fully homogenized wrought 718 material only $\gamma^{\prime \prime}, \gamma$, and delta phases will be found in addition to the primary MC and TiN phases. The precipitation of $\gamma / \gamma^{\prime}$ at temperatures of $1200^{\circ} \mathrm{F}$ or lower occurs very slowly in isothermal exposures up to 50 hours, but the precipitation will occur faster when stress is applied or in very long exposures.

The Laves phase was not found in this study and confirms the results of Decker (3) and Brooks and Bridges (5); however, the Laves phase has been found in 718 material which has had large amounts of cold work such as in bolt materials. This Laves phase is very small and would not present problems in LCF testing as residual Laves formed during solidification. As expected, no $\mathrm{M}_{6} \mathrm{C}$ was found in this study as the $0.07 \mathrm{Si}$ is too low for formation of the $\mathrm{M}_{6} \mathrm{C}$ type structure which was found in earlier studies.

The question of which phase, $\gamma^{\prime}$ or $\gamma$, forms first at temperatures of $1200^{\circ} \mathrm{F}$ or lower is a moot question since most standard heat treatments requires an initial heat treatment at $1400^{\circ} \mathrm{F}$ or $1325^{\circ} \mathrm{F}$ which is in the $\gamma^{\prime}$ precipitation range. Once the $\gamma^{\prime}$ is precipitated, the $\gamma^{\prime}$ phase can form in the areas between the $\gamma^{\prime}$ particles since the lower $\mathrm{Nb}$ content favors the $\gamma$ precipitation. Most 718 disks operate below $1200^{\circ} \mathrm{F}$ and the time for structural transitions in this temperature range are of the greatest interest.

\section{Acknowledgements}

The authors would like to thank Wyman-Gordon Company for the material used in this study. The financial support of The Niobium Products Company and WymanGordon Company is most appreciated. 


\section{References}

1. H. L. Eiselstein, "Metallurgy of a Columbium-Hardened Nickel-Chromium-Iron Alloy," ASTM STP 369, 1965, pp. 65-79.

2. J. F. Barker, "Long Time Behavior of Turbine Materials," GE Report R65FPD51, February 5, 1965.

3. 'R. F. Decker, "Strengthening Mechanisms in Nickel-Base Superalloys," presented at the Steel Strengthening Mechanisms Symposium, Zurich, Switzerland, 1969.

4. W. J. Boesch and H. B. Canada, "Precipitation Reactions and Stability of $\mathrm{Ni}_{3} \mathrm{Cb}$ in Inconel 718 Alloy,": 1968 Seven Springs International Symposium.

5. J. W. Brooks and P. J. Bridges, "Metallurgical Stability of Inconel Alloy 718," Superalloys 1988 Symposium. 